\title{
Arquitetura, cultura escolar e as práticas de educação física: a relevância dos pátios em instituições salesianas no início do Século XX
}

Architecture, school culture and physical education practices:

the relevance of patios in Salesian institutions in early of 20th century

Arquitectura, cultura escolar y prácticas de educación física:

la relevancia de los patios en las instituciones salesianas de principios del Siglo XX

\author{
Diego Ferreira Lima \\ Universidade Estadual de Campinas (Brasil) \\ https://orcid.org/0000-0003-3078-7302 \\ http://lattes.cnpq.br/6532457689268102 \\ diego.edfisica.ferreira@gmail.com \\ Edivaldo Gois Junior \\ Universidade Estadual de Campinas (Brasil) \\ https://orcid.org/0000-0002-0521-1937 \\ http://lattes.cnpq.br/3126832317253330 \\ gois@unicamp.br
}

\section{Resumo}

A presente pesquisa teve como objetivo analisar a representação do pátio como constituinte do espaço escolar de estabelecimentos educacionais salesianos, em específico, o Colégio Salesiano Santa Rosa e o Liceu Coração de Jesus. Em um recorte temporal pertinente às primeiras décadas do século $\mathrm{XX}$, a pesquisa documental teve como fontes: anuários, livros de registro e fotografias. A análise dos dados permitiu observar que nos pátios salesianos as práticas de educação física estavam muito presentes, e envolvidas em um processo de inter-relação entre diferentes culturas escolares marcadas por pedagogias modernas e um projeto educacional católico.

Palavras chave: História das instituições escolares. Arquitetura escolar. Educação Física. 


\begin{abstract}
This research aimed to analyze the representation of the patio as a school space of Salesian educational institutes, in particular, the Colégio Salesiano Santa Rosa and the Liceu Coração de Jesus. The study had as its time frame the first decades of the 20th century, and the documentary research had as sources: yearbooks, record books, and photographs. From the analysis of the data, we observed that physical education practices were very present in those patios, engaged by an interrelation process between different school cultures, inspired by modern pedagogies and a Catholic educational project.
\end{abstract}

Keywords: History of schools. School Architecture. Physical education.

\title{
Resumen
}

Esta investigación tuvo como objetivo analizar la representación del patio como un componente del espacio escolar de los establecimientos educativos salesianos, en particular, el Colégio Salesiano Santa Rosa y el Liceu Coração de Jesus. En un marco de tiempo pertinente a las primeras décadas del siglo XX, la investigación documental tuvo como fuentes: anuarios, libros de registro y fotografías. El análisis de los datos permitió observar que en los patios salesianos las prácticas de educación física estaban muy presentes e involucraban un proceso de interrelación entre las diferentes culturas escolares marcadas por las pedagogías modernas y un proyecto educativo católico.

Palabras claves: Historia de las instituciones escolares. Arquitectura escolar. Educación Física. 


\section{Introdução}

A presente pesquisa tem como objetivo analisar a representação do pátio como constituinte do espaço escolar de estabelecimentos educacionais salesianos, em específico, o Colégio Salesiano Santa Rosa e o Liceu Coração de Jesus. A historiografia da arquitetura escolar brasileira nos últimos anos ganhou importância nas pesquisas da área e para Ermel e Bencostta (2019a, p. 2) "algumas lacunas necessitam ser melhor investigadas, tanto do ponto de vista dos recortes temporais como de novas prospecções temáticas". Nesta discussão em particular, os autores Ermel e Bencostta (2019a) afirmam que as lacunas existentes neste campo residem ainda na necessidade de precisar como ocorreram a circulação das ideias pedagógicas em âmbito internacional em comparação com perspectivas nacionais e regionais em diferentes tempos, mas sobretudo no fim do século XIX e primeiras décadas do século $\mathrm{XX}^{1}$. Não pretendemos aqui de modo algum preencher estas lacunas, mas sim colaborar de maneira original na análise do pátio como elemento da arquitetura escolar e suas relações com uma pedagogia traduzida em práticas de educação física (GOIS JUNIOR; SOARES, 2018).

Neste estudo, como recorte temporal, optou-se pelas três primeiras décadas do século $\mathrm{XX}$, momento em que os espaços escolares (prédios e casas) passaram por grandes reformas na tentativa de responder às novas demandas sociais ligadas aos discursos de modernização das principais cidades brasileiras (BENCOSTTA, 2005). Segundo Silva, Rizzini e Silva (2012), os espaços escolares e suas arquiteturas integravam o projeto de remodelação dos comportamentos e costumes da população.

A escolha dessas instituições justifica-se por ambas serem caracterizadas como os primeiros estabelecimentos educacionais salesianos no século XIX em solo brasileiro, sendo responsáveis pela educação de um expressivo número de jovens oriundos das elites do Rio de Janeiro e de São Paulo. O Colégio Salesiano Santa Rosa, em Niterói, foi a primeira instituição de ensino desta congregação católica fundada no Brasil, em 1883. Já o Liceu Coração de Jesus, sediado na cidade de São Paulo, foi fundado em 1885. A organização destas duas primeiras escolas foi seguida das fundações de instituições nas cidades de Recife, Campinas, Lorena, e Cuiabá, ainda no século XIX (CASTANHO, 2008).

Por meio de uma perspectiva teórica identificada com a história cultural (BURKE, 2008), é possível encarar os pátios dos estabelecimentos como uma materialização de uma cultura escolar (JULIA, 2001), em particular, constituída no âmbito de uma congregação católica. Para Julia (2001), embora a cultura escolar represente "um conjunto de normas que definem conhecimentos a ensinar e condutas a inculcar, e um conjunto de práticas que permitem a transmissão desses conhecimentos e a incorporação desses comportamentos" (p. 10), pode-se também neste âmbito compreender as culturas infantis, por exemplo "que se desenvolvem nos pátios de recreio" (JULIA, 2001, p. 11). Neste sentido, na perspectiva de Dominique Julia, um colégio religioso pode deixar de ser apenas um local de aprendizagem de saberes para tornarse também um lugar de incorporação de comportamentos e hábitos que transcendem a formação cristã e as aprendizagens disciplinares (FARIA FILHO; VIDAL; PAULILO, 2004). Além disto, é preciso dizer que a cultura escolar passa a ser compreendida em sua pluralidade. Em outras palavras, falamos em culturas escolares, pois há de se considerar, conforme o objeto de estudo, as experiências de ensino, aprendizagem, convivência, socialização, regulação e subversão, que possibilitam a problematização dos processos de institucionalização da escola em seus diferentes níveis e modalidades de ensino (VIDAL, 2007). O estudo das culturas escolares

\footnotetext{
${ }^{1}$ Em 2019, o periódico História da Educação publicou um dossiê sobre o tema que contou com os estudos de Helfenberger e Schreiber (2019), Viola (2019), Ibarra (2019), Arata (2019), Ermel e Bencostta (2019b). O dossiê abordou a arquitetura destinada para a escola primária em diferentes espaços geográficos, entre as últimas décadas do século XIX e primeiras décadas do XX.
} 
considera os modos como os sujeitos se relacionam com as práticas, pois a escola é um lugar de constante negociação entre o imposto e o praticado (VIDAL, 2005; 2007).

A partir desta perspectiva, a análise da arquitetura e do espaço escolar transcende, desta forma, uma abordagem tradicional, pois permite a interpretação de outros discursos consubstanciados nas práticas que se organizavam naqueles espaços (VIÑAO FRAGO; ESCOLANO BENITO, 2001). Busca-se, dessa forma, o estudo do pátio salesiano como um constructo cultural que reflete, para além de sua materialidade, determinados discursos pedagógicos.

Para a interpretação e a constituição da presente narrativa, o acesso ao acervo histórico das instituições foi de suma importância. Em ambas as instituições, o diálogo foi realizado por meio de anuários escolares, livros de registro dos principais acontecimentos durante o ano no estabelecimento de ensino; materiais iconográficos que retratavam sobre as lentes salesianas seus cotidianos e documentos oficiais das instituições que constituem a memória dos estabelecimentos pesquisados.

A chegada da Congregação São Francisco de Sales ao Brasil, no final do século XIX, e o desenvolvimento dos seus estabelecimentos de ensino dialogaram diretamente com as reflexões acerca do sistema educacional brasileiro que pairavam nos ares na virada do século. Os salesianos já possuíam, no início do novo século, estabelecimentos educacionais nos principais estados brasileiros (AZZI, 2002), e intermediavam em suas práticas os preceitos propostos aos ambientes escolares desse período.

A educação escolar seria um dos elementos fundamentais para a construção do novo cenário político e econômico brasileiro, a República. A escola tornou-se um dos principais instrumentos para a difusão de novos hábitos e comportamentos considerados adequados.

Se a República era o lugar do homem novo, tornava-se necessário repensar esse ambiente, organizando-o, higienizando-o, ou seja, ordenando o espaço físico de cidade e, por consequência, o espaço físico da escola. Os edifícios escolares surgem, nesse momento, com uma finalidade específica - o lugar onde se processa a formação do cidadão (DÓREA, 2013, p. 169).

Dessa forma, se fez necessária a construção de ambientes próprios para uma nova educação escolar (BENCOSTTA, 2001; 2005). Para Faria Filho (1998), nos grandes centros urbanos, a construção da escola estará, então, intimamente ligada à construção simbólica da cidade e da reformulação da república. As localizações dos novos prédios escolares destacavam-se como figura representativa dos novos tempos.

Embebido por esse cenário, a Congregação Salesiana detinha especificações para a construção dos seus estabelecimentos educacionais no cotidiano citadino. Para Higino (2006), a congregação priorizava em sua escolha lugares que proporcionassem proteção e um potencial crescimento aos seus projetos. Dessa forma, as instituições educacionais salesianas difundiram-se primeiramente pelos centros e capitais, por exemplo, o Colégio Salesiano Santa Rosa em Niterói, capital fluminense, e o Liceu Coração de Jesus na capital paulista, ambos inaugurados no final do século XIX.

As escolas passaram a ser construídas com os mais modernos preceitos pedagógicos, higiênicos e arquitetônicos. Estas prerrogativas expõem o projeto de construção desses novos prédios escolares a uma perspectiva que extrapola o campo educacional. No novo projeto para a educação brasileira, estaria presente na constituição de seus estabelecimentos o diálogo entre diversas ciências e uma escola atenta à saúde, pautada em normas e regras estipuladas pela higiene como normas de bem viver (ROCHA, 2017). Nas questões arquitetônicas, estes novos prédios eram construídos para serem vistos, admirados e 
reverenciados, servindo de exemplo a outros estabelecimentos, e para funcionarem como modeladores de hábitos, atitudes e sensibilidades (FARIA FILHO, 1998).

Os prédios salesianos não ficaram fora desses padrões. Seus estabelecimentos eram representados por grandiosas fachadas, anunciando suas modernas construções e espaços internos que responderiam às necessidades de um espaço específico para a educação da infância brasileira. O Liceu Coração de Jesus representa perfeitamente esse diálogo. Sendo exemplo às outras diversas instituições educacionais salesianas, a arquitetura do liceu paulistano recebeu menções em diversos documentos da própria congregação. Uma passagem intitulada Lyceu Salesiano - As nossas impressões, texto publicado no anuário da instituição coirmã Liceu Nossa Senhora Auxiliadora de Campinas, descreve detalhadamente a admirada arquitetura desse estabelecimento.

O Edifício consta de um corpo central, um lateral à esquerda com três andares, e outro a direita e um magnífico salão, destinado aos futuros gabinetes de physica, museus e salas para aula.

O corpo central é de estylo romano, com três andares.

A entrada é de um aspecto encantador, com um grande átrio na frente e um corredor circular que serve para recreio em tempo chuvoso[...].

Atraz do edifício se estendem belas avenidas, um bello pomar e um aprazível parque para jogos esportivos. (LYCEU SALESIANO NOSSA SENHORA AUXILIADORA, 1914, p. 31).

Foi por meio desta representatividade na busca de uma educação além-muro e da modulação dos hábitos sociais que os prédios escolares passaram a constituir, com toda sua grandeza e magnitude, os espaços urbanos onde habitava e circulava uma juventude pertencente aos estratos sociais mais privilegiados daquelas cidades. Os novos estabelecimentos de ensino eram construídos no percurso da elite política e econômica dos grandes centros.

A rápida consolidação da Congregação Salesiana como um articulado sistema educacional em território brasileiro foi ocasionada por diversos fatores presentes no cenário sociopolítico e econômico do país. Entre eles, pode-se citar a necessidade de expansão do sistema educacional, uma concepção de educação voltada para um ensino profissional (formação de mão de obra), a atenção à juventude e a preservação dos dogmas da Igreja. Apesar dos pensamentos liberais que circulavam nos setores da sociedade ao final do século XIX e início do século XX, a Igreja manteve-se como uma forte instituição nas definições dos valores sociais (NAGLE, 2001). Na mesma direção, Cunha (2009) explica que o insucesso dos abolicionistas, que objetivavam a formação da mão de obra a partir da escolarização dos novos libertos, deu lugar às preferências das classes dirigentes, que apostaram essa função na religião e, preferencialmente, na Igreja.

Dessa forma, os salesianos constituíram no início do século XX uma forte rede de instituições educacionais consideradas referências na educação dos jovens brasileiros. Isso se deu, particularmente, por suas iniciativas de educação moral, profissional e religiosa, priorizando a instrução à juventude. Uma particularidade do projeto educacional salesiano era a relevância de práticas que poderiam fomentar o protagonismo juvenil, como jogos e atividades recreativas. Contudo, observamos nas fontes uma diversidade de práticas de educação física (GOIS JUNIOR; SOARES, 2018). Neste estudo, os esportes, os jogos, as brincadeiras, as ginásticas, todos foram compreendidos como práticas culturais nas quais uma instituição educacional católica imprimia seus valores mediante apropriações. Estas práticas (CERTEAU, 2011) - que aqui serão convencionadas pela expressão práticas de educação física constituem-se e dialogam com diferentes identidades, como por exemplo, as religiosas. 
No entanto, estas práticas estavam presentes em determinados espaços, onde suas arquiteturas são problematizadas e demandas por desejos de modernização das cidades. Entre tijolos e pedagogias:

A escola em suas diferentes concretizações é um produto de cada tempo, e suas formas construtivas são, além dos suportes de memória coletiva e cultural, a expressão simbólica dos valores dominantes nas diferentes épocas (VIÑAO FRAGO; ESCOLANO BENITO, 2001, p. 47)

A escola, a partir de um viés cultural, torna-se criação da própria sociedade, estando sujeita às mudanças históricas (VIÑAO FRAGO; ESCOLANO BENITO, 2001). Dessa forma, o estudo do espaço escolar nos aproxima das representações e apropriações de seu percurso (CHARTIER, 1990). A possibilidade da análise do espaço escolar recupera a história das instituições dando possibilidades a diversas interpretações (DÓREA, 2013). O espaço escolar, para além de sua arquitetura representativa de um momento histórico, possui por si só uma dimensão educativa. Essa dimensão é ratificada por Faria Filho (1998), que identifica nesse espaço um discurso que institui em sua materialidade um sistema de valores.

O espaço escolar, construído a partir da arquitetura, dos ambientes e das vivências, é identificado como um programa educador, ou seja, um elemento do currículo invisível, silencioso e oculto. Reflete, dessa forma, um determinado discurso que tem por objetivo orientar a prática educativa.

$\mathrm{Na}$ aproximação do cotidiano salesiano a partir da constituição dos espaços das suas instituições, observa-se a ação educativa de suas estruturas principalmente na distribuição de seus ambientes. Por intermédio de uma filosofia educativa pregada por Dom Bosco, na qual as práticas de educação física foram incentivadas no processo educativo dos jovens salesianos, alguns espaços ganharam destaque nos estabelecimentos educacionais da congregação. $\mathrm{Na}$ educação salesiana, a arquitetura escolar, atentando a distribuição de seus espaços, assume os valores educacionais propagados pela congregação de Dom Bosco. De forma explícita ou implícita, ela participa da modulação dos hábitos e comportamentos dos jovens salesianos. Viñao Frago e Escolano Benito (2001) descrevem essa relação da seguinte forma:

A arquitetura escolar é também por si mesma um programa, uma espécie de discurso que institui na sua materialidade um sistema de valores, como os de ordem, disciplina e vigilância, marcos para a aprendizagem sensorial e motora e toda uma semiologia que cobre diferentes símbolos estéticos, culturais e também ideológicos. (p.26)

Nesses critérios, um espaço no interior dos prédios salesianos ganhou destaque no programa pedagógico: o pátio. O pátio foi responsável por materializar uma parte importante da filosofia proposta por Dom Bosco aos seus seguidores. Nele, eram vivenciadas as diversas práticas de educação física, as atividades coletivas e recreativas, os festejos e as apresentações. O pátio identificava a instituição salesiana.

Porém, ao mencionar o pátio, espaço constitutivo dos estabelecimentos educacionais salesianos, não devemos limitá-lo a um espaço físico de paredes de alvenaria que ocupa a área central do estabelecimento. Nas reflexões de Fonseca (1998), o conceito de pátio da tradição salesiana se expande, sendo sinônimo de movimento, de juventude, de alegria. Em particular, qualquer ambiente aberto, com boa dimensão para a prática de brincadeiras, jogos e competições, que permitisse aglomerações de educandos, era considerado como o pátio. Dessa forma, esses ambientes se espalhavam no interior das instituições salesianas. 


\section{O protagonismo do pátio no Colégio Salesiano Santa Rosa}

O Colégio Salesiano Santa Rosa foi a primeira instituição educacional da Congregação São Francisco de Sales em solo brasileiro. Fundado em 1883, o estabelecimento recebeu alunos regularmente no início de 1884. Localizado em Niterói, capital do Rio de Janeiro, o colégio chega às primeiras décadas do século XX caracterizado como um grande estabelecimento escolar presente no cotidiano fluminense.

Como instituição salesiana, o colégio seguiu as orientações propagadas por Dom Bosco a toda a sua congregação. Entre elas, a abertura aos jogos, ao esporte, à dança, à festa e ao movimento juvenil, instrumentos pedagógicos que, para o sacerdote, tornavam o processo de escolarização mais agradável.

No caso do Colégio Salesiano Santa Rosa, o conjunto de prédios que abrigava o estabelecimento niteroiense apresentava-se, após diversas reformas e novas construções no início do século XX, como uma grande obra arquitetônica que corresponderia a todas as especificações exigidas para o período. Corredores largos, grandes janelas, salas de aula arejadas e bem iluminadas, laboratórios de ciências, enfermaria, consultório dentário, dormitórios, refeitórios e o pátio, espaços destinados à passagem e permanência dos educandos salesianos.

Imagem 1 - Primeira casa salesiana em Niterói.

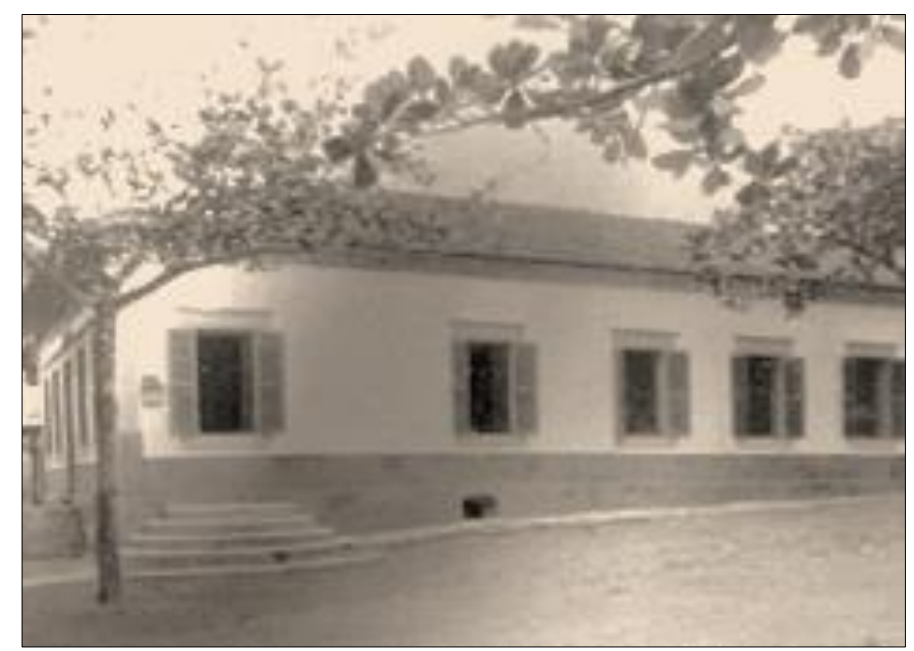

Fonte: Colégio Salesiano Santa Rosa (2004)

Imagem 2 - Primeiros pavilhões salesianos em Niterói.

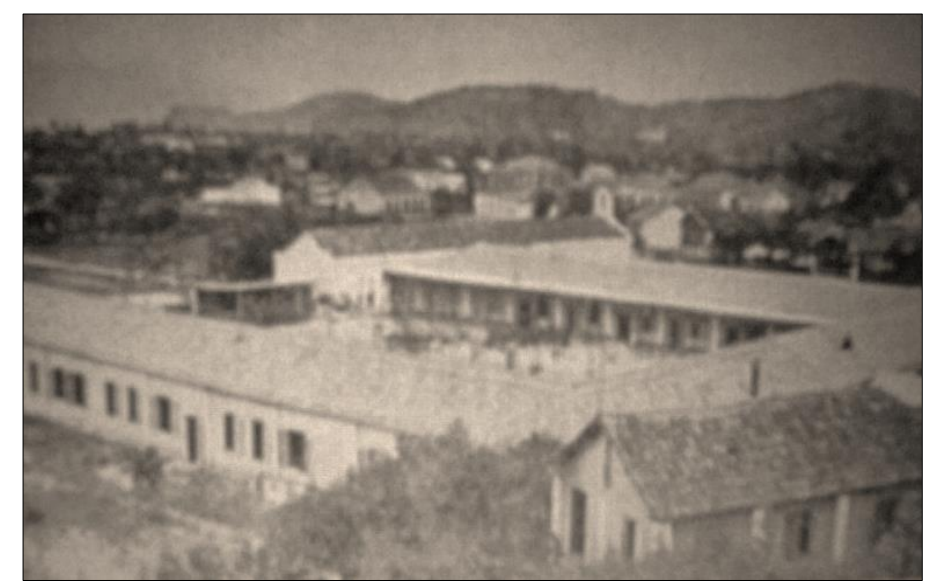

Fonte: Colégio Salesiano Santa Rosa (2004) 
Respondendo às novas exigências submetidas ao ambiente escolar pelos preceitos higienistas (STEPHANOU, 1999; ROCHA, 2003; GONDRA, 2004), a arquitetura salesiana moldava-se aos discursos de médicos e engenheiros divulgados nos diversos setores da sociedade em nome de um Brasil moderno (HERSCHMANN; PEREIRA, 1994). Em diversas passagens de seus anuários, documentos e relatórios, o termo "higiene" apresenta-se adjetivando a descrição dos ambientes internos do estabelecimento.

Diante da exposição dos seus espaços físicos, alguns ambientes em particular ganharam destaque: os amplos espaços abertos, os campos esportivos e os grandes pátios. Esses espaços eram destinados primordialmente para a vivência das diversas práticas de educação física que caracterizavam o sistema educacional elaborado por Dom Bosco.

Higino (2006) relata que esses ambientes foram, na construção do colégio, praticamente obrigatórios, dialogando com a pedagogia dos jogos proposta por Dom Bosco aos jovens em seus estabelecimentos. No Colégio Salesiano Santa Rosa, especificamente, a organização dos seus espaços deu-se da seguinte forma:

O terreno de mais de 100 mil m2 foi ocupado uma série de edifícios sólidos, bem arejados e adaptados às exigências de um bom colégio, com pátios amplos e arborizados para cada uma das seis divisões de alunos, campos para jogos, salão de teatro para representações dramáticas e conferências, laboratórios, gabinetes e museus. (HIGINO, 2006, p.25)

Posteriormente, adentrando nas primeiras décadas do século XX, com o crescimento e desenvolvimento das diversas práticas esportivas na cidade, o Colégio Salesiano alojaria no seu interior a marca dessas novas práticas sociais. Assim, os amplos espaços, pátios e campos, que inicialmente vivenciavam os jogos e o movimento livre, tornaram-se lugares específicos de determinadas práticas esportivas.

Os espaços abertos, os pátios e campos ganharam linhas, traves, redes, diversas bolas, raquetes, rodas e diversos instrumentos das modernas manifestações esportivas. O esporte, já consagrado no cotidiano citadino, mostrava-se cada vez mais presente nos espaços internos do colégio. Em concordância com Melo (2019), o esporte proporcionava uma nova sensibilidade de entretenimento na cidade de Niterói, já na década de 1890. A partir desses ambientes, percebe-se a relação que a instituição de ensino desenvolveu com o cotidiano da cidade na qual estava inserida. Seus espaços internos tornaram-se a representação desse diálogo.

No Colégio Salesiano Santa Rosa, as alterações sofridas em seus espaços, principalmente aqueles responsáveis pela vivência das práticas de educação física, revelam de forma contundente um projeto educacional que dava mais espaço para pedagogias consideradas modernas, como o esporte. Em 1927, uma proposta elaborada pelos superiores salesianos, com o objetivo de oficializar o ensino na instituição, argumentava com a seguinte exposição da instituição:

Considerando que esse instituto, perfeitamente aparelhado com edificios próprios, hygienicos, adequados, possuindo gabinetes de historia natural, physica e chimica, campos de sport e demais necessidades pedagógicas modernas, preenche os fins de educação e instrucção;

Considerando que esse instituto reúne assim, emfim, todos os requisitos de idoneidade para o exacto desempenho de sua alta missão cultural, e presta inestimável somma de benefícios a educação da infância desvalida ou necessitada (COLLEGIO SALESIANO SANTA ROZA, 1927, s.p.). 
A observação da distribuição espacial do Colégio Salesiano Santa Rosa permite diferentes análises que precipitam a rotina da instituição. Na presença e na ausência das paredes de seus prédios, notam-se o incremento das práticas higiênicas, do legado deixado por Dom Bosco nos pátios e da presença do esporte moderno nos espaços específicos. Todos esses espaços eram preenchidos diariamente por diversos educandos, que davam vida a cada metro do estabelecimento. Os movimentos espontâneos e livres dos inúmeros alunos recebidos pelos missionários davam ao dia letivo salesiano um momento ímpar na vida de cada participante.

Imagem 3 - Festa cívica no pátio salesiano.

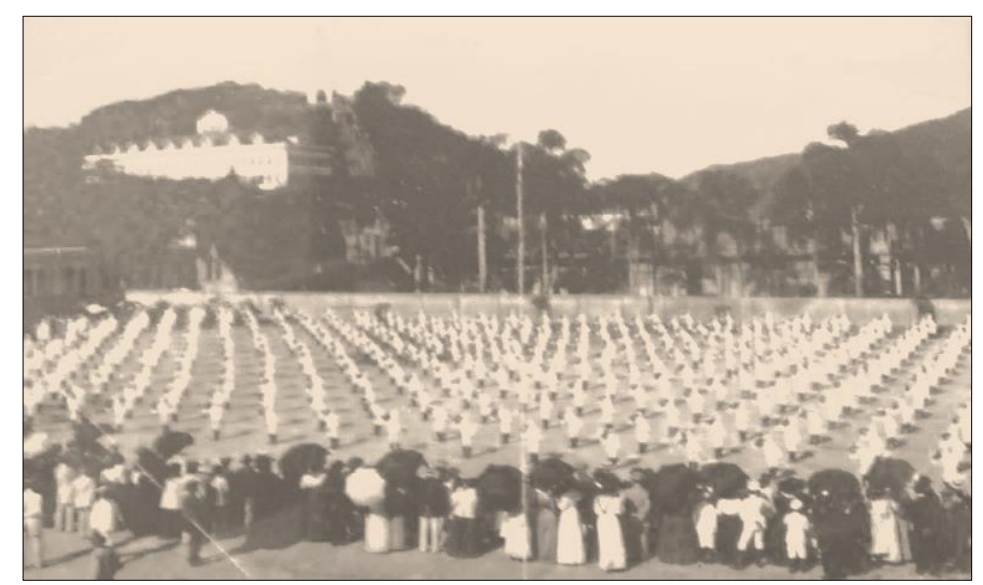

Fonte: Collegio Salesiano Santa Roza (1915)

O protagonismo do pátio no Colégio Salesiano Santa Rosa acompanha todo o percurso do estabelecimento niteroiense. Em cada reforma, mudança, adaptação, celebrações, homenagens, competições, o pátio estaria representado no cotidiano da instituição.

O pátio como espaço privilegiado destas práticas constituiu uma rica zona de contato, como uma área de convergência de distintas culturas escolares. No encontro entre a tradição salesiana inspirada na pedagogia de Dom Bosco e os discursos pedagógicos da escola moderna orientados pelo poder público, compreendemos que as práticas de educação física não eram apenas prescrições, pois se afirmavam entre diferentes culturas escolares e ganhavam novas dinâmicas a partir das experiências dos educandos.

Imagem 4 - Exercício de Gymnastica Sueca no Collegio Salesiano Santa Roza em Nitheroy.

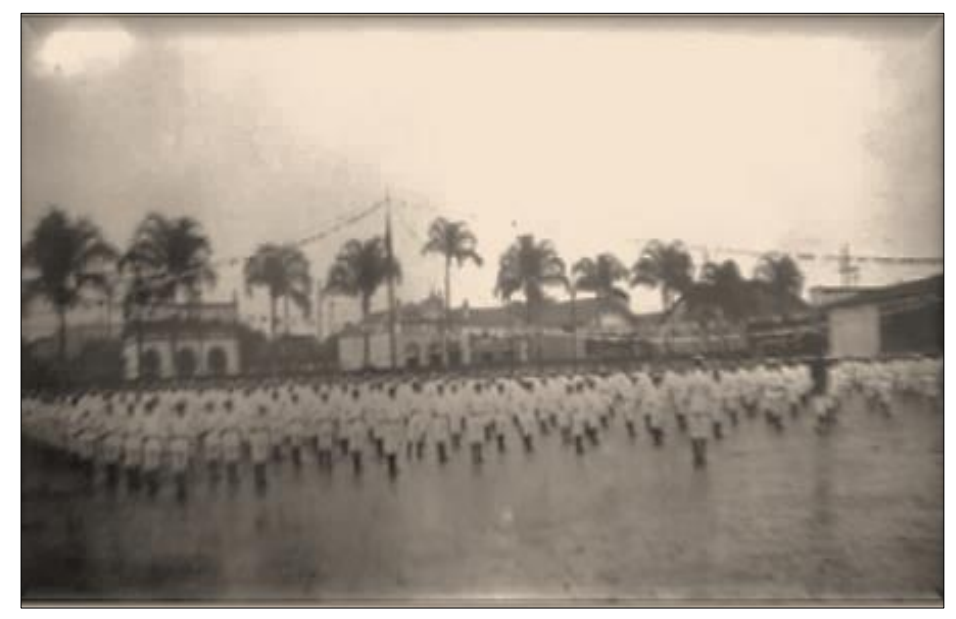

Fonte: Collegio Salesiano Santa Roza (1930). 


\section{O protagonismo do pátio no Liceu Coração de Jesus}

O segundo estabelecimento educacional analisado neste estudo foi o Liceu Coração de Jesus que, localizado na capital paulista, foi fundado no final do século XIX. Diferentemente do terreno para a construção do estabelecimento em Niterói, a aquisição do espaço para a construção da obra em São Paulo não iniciou em seu ponto zero. Os salesianos assumiram na capital paulista um prédio construído, que era um projeto de Liceu para a cidade de São Paulo que não chegou ao seu final (ISAÚ, 1985).

Aos poucos, o prédio localizado em Campos Elíseos foi progressivamente ganhando os traços e as características de um estabelecimento de ensino salesiano. Entre obras e reformas, um imponente prédio ganhou os contornos específicos da Congregação e, aos poucos, a fachada, os espaços internos, a distribuição espacial e toda estrutura foi adquirindo a peculiaridade das instituições de ensino de Dom Bosco.

Em relação à estrutura física do Liceu Coração de Jesus, ali também um espaço em específico era protagonizado: o pátio. Como já discutido, umas das características das instituições de ensino salesianas são os jogos, a música, o movimento e a alegria juvenil (AZZI, 1982).

Com isso, a preocupação com as práticas de educação física era relevante, pois na planta do grandioso complexo arquitetônico do Liceu Coração de Jesus, tinham destaque amplos espaços ao ar livre, como campos, quadras e pátios. Frequentemente, a descrição desses espaços era relatada em documentos, folhetins da época e no próprio anuário das instituições salesianas. Mas, em particular, o pátio era o melhor representante da alegria e do movimento livre propostos pela pedagogia de Dom Bosco. Foi neste espaço que as diversas práticas de educação física eram vivenciadas pelos educandos salesianos. Os pátios do Liceu Coração de Jesus eram a representação do movimento juvenil no interior da instituição. Na volta às aulas, era esse ambiente que anunciava o retorno do cotidiano do colégio.

Os pateos, dias antes tão pouco animados, readquiriam a vida alegre e tumultuosa de outr'ora. E que movimento! No anno passado eram uns 380 mais ou menos; este anno são 450 que se movem e se agitam, que fallam e riem, que saltam e correm por todos os dias. (LYCEU SAGRADO CORAÇÃO DE JESUS, 1916, p.7).

No Liceu Coração de Jesus, os pátios eram utilizados principalmente para os momentos de recreação dos jovens. Nesses momentos, sem nenhuma solenidade ou evento especial, o pátio era fotografado e registrado nos documentos oficiais que contariam a história da instituição.

Imagem 5 - Jogo “Estado” entre interno e externo, início 1906.

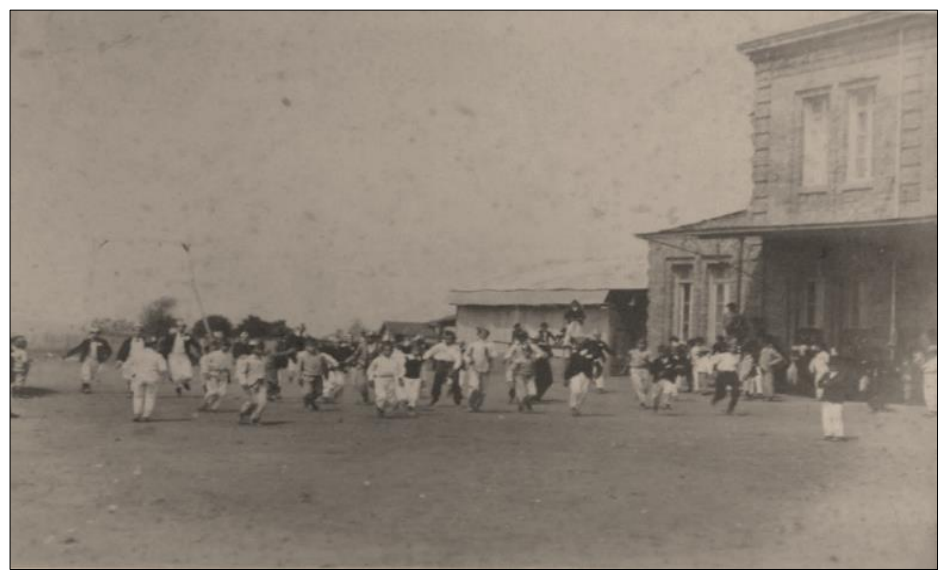

Fonte: Lyceu Salesiano Sagrado Coração de Jesus (1906). 
A recreação no pátio não era nenhuma solenidade oficial ou evento formal, mas era nesse momento que uma das maiores características da congregação se fazia presente. Era neste espaço que eram praticados também movimentos livres aos educandos, aspecto que Dom Bosco sempre enfatizou nos seus estabelecimentos de ensino.

Imagem 6 - Recreio no pátio do Liceu 1908.

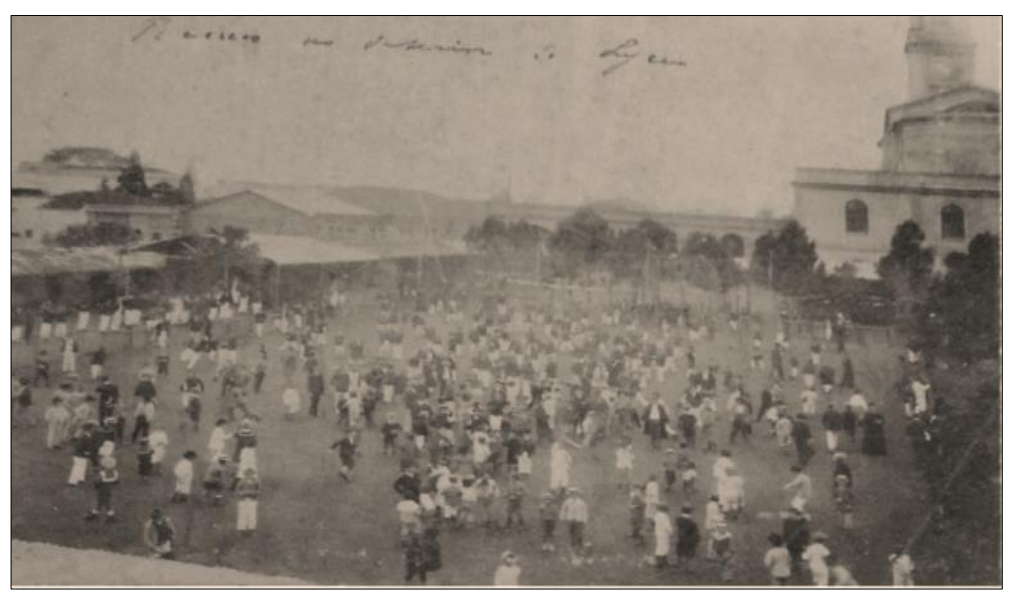

Fonte: Lyceu Salesiano Sagrado Coração de Jesus (1908).

As fotografias acima demonstram o protagonismo dado à dinâmica do pátio salesiano em dois momentos distintos. A primeira, em 1906, evidencia o pátio do Liceu como uma grande área aberta sem muitas construções ou delimitações. Desde sua fundação, no final do século XIX, até o limite do recorte temporal dessa pesquisa, o ano de 1930, o Liceu passou por diversas reformas, tornando o colégio cada vez mais apto à educação da juventude paulista. A simplicidade do terreno não impedia a prática dos jogos, dos movimentos e dos momentos de recreação entre os educandos salesianos.

O outro momento ilustrado pela fotografia acima é de um Liceu mais institucionalizado, com um número maior de alunos em seu pátio. Porém, o modo de prática vivenciada neste ambiente não se alterou; o pátio continuou sendo a materialização de uma pedagogia centrada em jogos recreativos, mas também esportes e ginásticas. A imagem como instrumento de preservação da memória da instituição captura aspectos que a caracterizam e criam sua identidade.

As fotografias expressam a trajetória da construção do Liceu, do estabelecimento doado à Congregação no final do século XIX ao imponente prédio do colégio no início do século XX. As reformas para a construção e melhoria de seus espaços foram contínuas, objetivando sempre a melhor forma de desenvolver a educação salesiana e responder às necessidades exigidas pelo poder público. Em meio a todo processo de reformas e construções, o pátio sempre era evidenciado. A reforma ocorrida em 1918 é relatada no anuário da seguinte forma:

E o vasto sobrado das aulas amplas, cheias de ar e transbordantes de luz, era sem duvida uma bela novidade para os recem-chegados.

O aumento dos pateos, pelo terreno ganho com a demolição das oficinas de mecânica e marcenaria, que se haviam transferido para o Bom Retiro, era outro progresso que o pessoal muito ainda apreciava mais do que o do edifício novo, pois que a acquisição de mais algumas centenas de metros quadrados para correr, pular, folgar, em rectas e curvas mais amplas e caprichosas, era para eles uma conquista de valor somente comparavel ao 
terreno que, palmo a palmo se disputa ao inimigo nos campos de batalha (LYCEU SAGRADO CORAÇÃO DE JESUS, 1918, p.5-6).

O pátio quase sempre estava presente nas reformas, objetivando cada vez mais adequar o espaço físico do Liceu às exigências educacionais da época e aos métodos educativos salesianos. Outras reformas ocorridas nas instituições destacavam os locais de vivências como, por exemplo, as áreas livres, abertas e os terraços. Na construção do novo edifício, mais uma vez, os espaços destinados à recreação foram ressaltados. "Uma parte importante da nova construção e o amplo terraço, destinado a ser o pateo dos semi-internos. Mede 520 metros quadrados. Dalli se descortina magnifico panorama. Será um recreio hygienico e folgado, sem pó e sem bolas de futebol." (LYCEU SAGRADO CORAÇÃO DE JESUS, 1925, p.6).

O anuário de 1925 relatou que os pátios pareciam pequenos para o número de alunos, de modo que os terraços passaram a ser utilizados para ampliar os espaços, descongestionando aqueles ambientes nas horas destinadas ao recreio. Uma opção para a melhor convivência foi dividir o horário de recreio dos alunos em dois períodos. O Liceu registrava mais de 10.000 metros quadrados de áreas abertas destinadas à recreação e à vivência de diversas práticas de educação física, e essa dimensão fora alcançada a partir das seguintes medidas:

Area total da quadra do Lyceu 15.200 m. q.

Area total edificada $5.500 \mathrm{~m}$. q.

Area descoberta para recreios $7.235 \mathrm{~m}$. q.

Area coberta para recreios (alpendres) 2.465 m. q.

Area do terraço do Externato 520 m. q.

Donde se conclue que o Lyceu dispõe de 10.220 m. q. para recreio. (LYCEU SAGRADO CORAÇÃO DE JESUS, 1925, p.6).

As diversas reformas realizadas no início do século $\mathrm{XX}$, que geralmente evidenciavam a questão dos pátios e os espaços de recreação, eram embebidas por preceitos higiênicos que pairavam no cotidiano dos grandes centros urbanos e faziam moradia nos estabelecimentos educacionais. Nos documentos responsáveis por expor e divulgar as reformas e suas necessidades à sociedade paulistana, as condições higiênicas estavam presentes nas amplas acomodações dos alunos, nas salas arejadas e nos terraços sem a poeira dos campos de terra batida.

As exigências higiênicas presentes nas grandes cidades no início do século XX implantaram orientações nos estabelecimentos educacionais, incentivadas e divulgadas pelo poder público, médicos e intelectuais (SOUZA, 1997; STEPHANOU, 1999). O Liceu, que em número de alunos já se tornava a principal instituição salesiana em solo brasileiro, frequentemente dependia de doações populares e governamentais para manter-se e realizar seus trabalhos educacionais e, por isso, não poderia fugir dos preceitos higienistas propagados por médicos, engenheiros e educadores (HERSCHMANN; PEREIRA, 1994). A higiene, além de exigência, passou a ser propaganda de um estabelecimento educacional moderno e integrado com a sociedade e suas novas demandas.

Na década de 1920, a instituição já demostrava a imponência dos seus prédios, que representavam uma declarada publicidade da educação salesiana. No anuário de 1921, na introdução ao seu Estatuto, foi descrita a instituição higiênica a partir de seus ambientes de convívio.

Hygiene e conforto

São excelentes as condições hygienicas do estabelecimento. Vastos salões para dormitórios e aulas, fartamente servidos de ar e luz; pateos de recreio espaçosos com imensas áreas para toda a sorte de jogos ao ar livre; grandes 
reservatórios de agua filtrada em todas as dependencias do estabelecimento e em todos os pateos de recreio (mais de quatro mil litros de agua filtrada fornecem constantemente os seus grandes filtros de pressão), optimas instalações sanitárias, lavatórios com agua corrente abundantíssima; instalações com agua fria e quente; excelente cosinha de montagem moderna; uma optima enfermaria construída expressamente, dotada de todos os recursos modernos, com grandes salas e quartos para doentes; pharmacia completa e pharmaceutico residente no estabelecimento; visita medica diária de um clinico competentissimo; gabinete dentário de primeira ordem, com dois profissionais internos diplomados; salão de barbeiro modernissimo, com pessoal interno; numa palavra, todos os recursos de hygiene e conforto que, unidos á educação moral, intelectual e artística, possam tornar a vida collegial, a um tempo sã, profícua, alegre e aprazível, de modo a formarem-se meninos e moços sadios, robusto e prendados de corpo e espirito. (LYCEU SAGRADO CORAÇÃO DE JESUS, 1921, p. 132).

Divulgado na sociedade paulista, o Liceu Coração de Jesus adquire grande prestígio como instituição educacional. O número de educandos foi crescendo durante a sua trajetória. No ano de sua fundação (1885), a instituição atendia poucos alunos oriundos de vilas próximas. Em 1930, de acordo com o seu anuário, o Liceu contabilizava 1280 educandos oriundos das diversas cidades paulistas e de outros estados brasileiros. (LYCEU SAGRADO CORAÇÃO DE JESUS, 1930).

O pátio do Liceu Coração de Jesus foi o espaço de manifestação das diversas práticas de educação física que movimentaram o cotidiano da instituição. Da recreação e brincadeiras proporcionadas pela tradição da Congregação salesiana ao esporte moderno que, a partir do meio citadino, adentrou o estabelecimento, o pátio do Liceu foi o espaço de representação e mediação entre diferentes culturas escolares, como a tradição salesiana, os ideais da escola moderna, mas também as particularidades de cada instituição salesiana

\section{Considerações finais}

A marca das instituições salesianas no início do século passado teve como uma das suas principais características o seu acervo arquitetônico. Imponentes prédios que, por meio de novas construções, reformas e adaptações representaram o ensino salesiano em solo brasileiro. No interior dos estabelecimentos um espaço em especial ganhou destaque: o pátio.

Definido por um conceito amplo, o pátio salesiano protagonizou os principais momentos das instituições analisadas, o Colégio Salesiano Santa Rosa e o Liceu Coração de Jesus. O pátio salesiano, originado na própria tradição da congregação de Dom Bosco, foi o local responsável por perpetuar os ensinamentos do sacerdote italiano. A recreação, os jogos, os movimentos livres no pátio faziam parte do momento prazeroso que dava leveza à educação salesiana. Todavia isto não significava a ausência de esportes e ginásticas marcados pela educação moderna. Pelo contrário, o pátio salesiano também se mostrou como um relevante mediador entre diferentes culturas escolares. As manifestações vivenciadas nesses espaços representavam intermediações entre os ideais higienistas de uma escola moderna e a tradição salesiana católica. Não muito distante do que observou Cancilini (2003) no campo das artes latino-americanas, esta heterogeneidade multitemporal é consequência de uma história na qual a modernização operou poucas vezes mediante a substituição do tradicional pelo moderno. Estas contradições eram propícias para que apenas as elites brasileiras pudessem ter acesso às práticas tidas como modernas, aos confortos de uma civilidade urbana, higiênica, racional, 
conforme as prescrições de médicos e intelectuais, mas também concomitantemente mantinham as estruturas sociais em confianças pré-modernas, como a educação religiosa.

Analisar os pátios dos estabelecimentos educacionais salesianos nos envolve em um distinto processo de reflexão que, a partir de acervos culturais e fundamentado em uma metodologia que se apropria de novas fontes, como as estruturas e os espaços escolares, contam outra história das instituições escolares.

\section{Referências}

ARATA, Nicolás. Un episodio de la cultura material: la inauguración de 54 edificios escolares en la ciudad de Buenos Aires (1884-1886). Hist. Educ., Santa Maria, v.23, e84235, 2019. DOI: https://doi.org/10.1590/2236-3459/84235.

AZZI, Riolando. A obra de Dom Bosco no Brasil: cem anos de história. Barbacena: Centro Salesiano de Documentação e Pesquisa, 2002. v. III.

AZZI, Riolando. Os salesianos no Brasil a luz da história. São Paulo: Salesiano Dom Bosco, 1982. BENCOSTTA, Marcus Levy Albino. Arquitetura e espaço escolar: reflexões acerca do processo de implantação dos primeiros grupos escolares de Curitiba (1903-1928). Educação em revista, Curitiba, n.18, p.103-141, dez. 2001. DOI: https://doi.org/10.1590/0104-4060.236

BENCOSTTA, Marcus Levy Albino (Org.) História da Educação, Arquitetura e Espaço Escolar. São Paulo: Cortez Editora, 2005.

BURKE, Peter. O que é História Cultural? 2. ed. Rio de Janeiro: Jorge Zahar Editora. 2008.

CANCLINI, Nestor García. Culturas Hibridas: estratégias para entrar e sair da modernidade. 4. ed. São Paulo: EdUSP, 2003.

CASTANHO, Sergio. A institucionalização escolar entre 1879 e 1930. Série-Estudos, Campo Grande, n. 25, jun. 2008. DOI: https://doi.org/10.20435/serie-estudos.v0i25.219.

CERTEAU, Michel de. A escrita da história. Rio de Janeiro: Forense, 2011.

CHARTIER, Roger. A História Cultural: entre práticas e representações. Lisboa: DIFEL, 1990.

CUNHA, Luiz Antonio. Educação, Estado e Democracia no Brasil. 6. ed. Cortez, Niterói: Editora da Universidade Federal Fluminense; Brasília: FLASCO do Brasil, 2009.

DÓREA, Célia Rosângela Dantas. A arquitetura escolar como objeto de pesquisa em História da Educação. Educação em revista, Curitiba, n.49, p.161-181, set.2013. DOI: https://doi.org/10.1590/S0104-40602013000300010.

ERMEL, Tatiane de Freitas; BENCOSTTA, Marcus Levy. Arquitetura escolar: diálogos entre o global, nacional e regional na história da educação. História Educ., Santa Maria, v.23, p.1- 6, 2019a. DOI: https://doi.org/10.1590/2236-3459/88785.

ERMEL, Tatiane de Freitas; BENCOSTTA, Marcus Levy. Escola graduada e arquitetura escolar no Paraná e Rio Grande do Sul: a pluralidade dos edifícios para a escola primária no cenário brasileiro (1903-1928). Hist. Educ., Santa Maria, v. 23, e83527, 2019b. DOI: https://doi.org/10.1590/2236-3459/83527. 
FARIA FILHO, Luciano Mendes. O espaço escolar como objeto da história da educação: algumas reflexões. Educação e pesquisa, São Paulo, v.24, n.1, p.141-159, jan.1998. DOI: https://doi.org/10.1590/S0102-25551998000100010.

FARIA FILHO, Luciano Mendes; VIDAL, Diana Gonçalves; PAULILO, André Luiz. A cultura escolar como categoria de análise e como campo de investigação na história da educação brasileira. Educação e Pesquisa, São Paulo, v.30, n.1, p.139-159, abr. 2004. DOI: https://doi.org/10.1590/S1517-97022004000100008.

FONSECA, Jairo de Matos. Sistema Preventivo de Dom Bosco. Belo Horizonte: CESAP, 1998. GOIS JUNIOR, Edivaldo; SOARES, Carmen Lucia. Os comunistas e as práticas de educação física dos jovens na década de 1930 no Rio de Janeiro. Educação e pesquisa, São Paulo, v. 44, p. 1-19, 2018.

GONDRA, José G. Artes de civilizar: medicina, higiene e educação escolar na Corte Imperial. Rio de Janeiro: EdUERJ, 2004. DOI: https://doi.org/10.1590/s1678-4634201844175380.

HERSCHMANN, Micael M.; PEREIRA, Carlos Alberto M. Invenção do Brasil Moderno: Medicina, Educação e Engenharia nos anos 20-30. Rio de Janeiro: Rocco, 1994.

HELFENBERGER, Marianne; SCHREIBER, Catherina. Construindo cidadãos: arquitetura da escola e seu programa social - visões comparativas da Suíça e de Luxemburgo nos séculos XIX e XX. Hist. Educ., Santa Maria, v. 23, e82303, 2019. DOI: https://doi.org/10.1590/2236-3459/82303.

HIGINO, Elizete. Um século de tradição: a banda de música do Colégio Salesiano Santa Rosa. 2006. Dissertação (Mestrado em História) - Fundação Getúlio Vargas, Rio de Janeiro 2006.

IBARRA, Carlos Ortega. Una arquitectura escolar nacional y popular durante la revolución constitucionalista de 1914-1917. Hist. Educ., Santa Maria, v.23, e83400, 2019. DOI: https://doi.org/10.1590/2236-3459/83400.

ISAÚ, Manoel. Liceu Coração de Jesus. São Paulo: Editora Salesiana, 1985.

JULIA, Dominique. A cultura escolar como objeto histórico. Revista Brasileira de História da Educação, v.1, n.1, p.9-43, jan./jun. 2001.

MELO, Victor Andrade. O espetáculo que educa o corpo: clubes atléticos na cidade de Niterói dos anos 1880. Revista História da Educação, Pelotas, v.23, p.1-34, 2019. DOI: https://doi.org/10.1590/2236-3459/85836.

NAGLE, Jorge. Educação e Sociedade na Primeira República. Rio de Janeiro: DP\&A, 2001.

ROCHA, Heloisa Helena Pimenta. A higienização dos costumes: educação escolar e saúde no projeto do Instituto de Hygiene de São Paulo. Campinas: Mercado de Letras; Fapesp, 2003.

ROCHA, Heloisa Helena Pimenta, Regras de bem viver para todos: a Bibliotheca Popular de Hygiene do Dr. Sebastião Barroso. Campinas: Mercado de Letras; Fapesp, 2017. 
SILVA, José Cláudio Sooma; RIZZINI, Irma; SILVA, Maria de Lourdes. Remodelar a capital carioca e sua gente: educação e prevenção nos anos 1920. Revista História da Educação, Pelotas, v.16, p.198-224, 2012. DOI: https://doi.org/10.1590/S2236-34592012000200010.

SOUZA, Rosa Fátima de. Templos de civilização: um estudo sobre a implantação dos Grupos Escolares no estado de São Paulo (1890-1910). 1997. Tese (Doutorado em Educação) Faculdade de Educação, Universidade de São Paulo, São Paulo, 1997.

STEPHANOU, Maria. Tratar e educar: discursos médicos nas primeiras décadas do século XX. 1999. Tese (Doutorado em Educação) - Faculdade de Educação, Universidade Federal do Rio Grande do Sul, Porto Alegre. 1999. 2v.

VIÑAO FRAGO, A; ESCOLANO BENITO, A. Currículo, espaço e subjetividade: a arquitetura como programa. Rio de Janeiro: DP\&A, 2001.

VIDAL, Diana Gonçalves. Culturas escolares: estudo sobre práticas de leitura e escrita na escola pública primária (Brasil e França, final do século XIX). Campinas: Autores Associados, 2005.

VIDAL, Diana Gonçalves. Culturas escolares: entre la regulación y el cambio. Propuesta Educativa, n. 28, p. 28-37, 2007. DOI: https://www.redalyc.org/articulo.oa?id=403041700005.

VIOLA, Valeria. Arquitetura escolar durante o fascismo em Itália. Hist. Educ., Santa Maria, v.23, e82782, 2019. DOI: https://doi.org/10.1590/2236-3459/82782.

\section{Fontes}

COLÉGIO SALESIANO SANTA ROSA. Anuário de 2003 - 2004. Niterói: Memorial Histórico do Colégio Salesiano Santa Rosa, 2004.

COLLEGIO SALESIANO SANTA ROZA. Proposta de oficialização. Niterói: Memorial Histórico do Colégio Salesiano Santa Rosa, 1927.

COLLEGIO SALESIANO SANTA ROZA. Anuário de 1915. Niterói: Memorial Histórico do Colégio Salesiano Santa Rosa, 1915.

COLLEGIO SALESIANO SANTA ROZA. Anuário de 1930. Niterói: Memorial Histórico do Colégio Salesiano Santa Rosa, 1930.

LYCEU SALESIANO NOSSA SENHORA AUXILIADORA. Anuário de 1914. Campinas: Lyceu Salesiano Nossa Senhora Auxiliadora, 1914.

LYCEU SALESIANO SAGRADO CORAÇÃO DE JESUS. Anuário de 1916. São Paulo: Lyceu Salesiano Sagrado Coração de Jesus, 1916.

LYCEU SALESIANO SAGRADO CORAÇÃO DE JESUS. Anuário de 1918. São Paulo: Lyceu Salesiano Sagrado Coração de Jesus, 1918.

LYCEU SALESIANO SAGRADO CORAÇÃO DE JESUS. Anuário de 1921. São Paulo: Lyceu Salesiano Sagrado Coração de Jesus, 1921. 
LYCEU SALESIANO SAGRADO CORAÇÃO DE JESUS. Anuário de 1925. São Paulo: Lyceu Salesiano Sagrado Coração de Jesus, 1925.

LYCEU SALESIANO SAGRADO CORAÇÃO DE JESUS. Anuário de 1930. São Paulo: Lyceu Salesiano Sagrado Coração de Jesus, 1930.

LYCEU SALESIANO SAGRADO CORAÇÃO DE JESUS. Jogo "Estado" entre interno e externo, início 1906. 1906. 1 fotografia. Memorial do Colégio Salesiano Coração de Jesus. Pasta de fotos n. 3, Lyceu Coração de Jesus 1902 - 1907, cartelas 38 a 84.

LYCEU SALESIANO SAGRADO CORAÇÃO DE JESUS. Recreio no pátio do Lyceu 1908. 1908. 1 fotografia. Memorial do Colégio Salesiano Coração De Jesus. Pasta de fotos n. 3, Lyceu Coração de Jesus 1908 - 1914, cartelas 85 a 126. 